\title{
Mesophotic coral depth acclimatization is a function of host-specific symbiont physiology
}

\author{
Maren Ziegler ${ }^{1,2,3}$, Cornelia M. Roder ${ }^{1}$, Claudia Büchel ${ }^{2}$ and Christian R. Voolstra ${ }^{1 *}$ \\ ${ }^{1}$ Reef Genomics Lab, Red Sea Research Center, King Abdullah University of Science and Technology, Thuwal, Saudi Arabia \\ ${ }^{2}$ Department of Biosciences, Institute of Molecular Biosciences, Goethe University Frankfurt, Frankfurt am Main, Germany \\ ${ }^{3}$ Ichthyology Section, Senckenberg Research Institute and Natural History Museum, Frankfurt am Main, Germany
}

\section{Edited by:}

Andrew Stanley Mount, Clemson University, USA

Reviewed by:

Daniel J. Thornhill, Defenders of

Wildlife, USA

Cory Douglas Bishop, St.

Francis-Xavier University, Canada

*Correspondence:

Christian R. Voolstra, Reef

Genomics Lab, Red Sea Research

Center, 4700 King Abdullah

University of Science and

Technology (KAUST), Building 2,

Office 2226, 23955-6900 Thuwal,

Saudi Arabia

e-mail: christian.voolstra@

kaust.edu.sa
Mesophotic coral ecosystems receive increasing attention owing to their potential as deep coral refuges in times of global environmental change. Here, the mechanisms of coral holobiont photoacclimatization over a $60 \mathrm{~m}$ depth gradient in the central Red Sea were examined for the four coral genera Porites, Leptoseris, Pachyseris, and Podabacia. General acclimatization strategies were common to all host-symbiont combinations, e.g., Symbiodinium cell densities and photoprotective (PP) to light-harvesting pigment ratios both significantly decreased with water depth. Porites harbored Symbiodinium type C15 over the whole $60 \mathrm{~m}$ depth range, while Pachyseris and Podabacia had limited vertical distributions and hosted mainly Symbiodinium type C1. Symbiodinium type C15 had generally higher xanthophyll de-epoxidation rates and lower maximum quantum yields than $\mathrm{C} 1$, and also exhibited a strong photoacclimatory signal over depth that relates to the large distribution range of Porites. Interestingly, the coral host had an effect on Symbiodinium pigment composition. When comparing Symbiodinium type $\mathrm{C} 1$ in Podabacia and Pachyseris, the ß-carotene chl $\mathrm{a}^{-1}$, the peridinin chl $\mathrm{a}^{-1}$, and diadinoxanthin $\mathrm{chl} \mathrm{a}^{-1}$ ratios were significantly different between host species. Our data support a view that depth acclimatization of corals in the mesophotics is facilitated by Symbiodinium physiology, which in turn is host-specific.

Keywords: coral reef, mesophotic coral, Red Sea, Symbiodinium, photosynthetic pigments

\section{INTRODUCTION}

Light in the ocean decreases exponentially with depth and it is one of the most important factors shaping coral communities (Falkowski and Dubinsky, 1981; Dubinsky et al., 1984). Below $30 \mathrm{~m}$ depth, mesophotic coral communities act as an extension of shallow water reefs until the bottom of the photic zone (Kahng et al., 2010). While light limitations constraint most Symbiodinium-bearing corals to depths shallower than $90 \mathrm{~m}$, photosynthetically active corals can be found as deep as $145 \mathrm{~m}$ in the Red Sea owing to the transparency of the water column (Schlichter et al., 1986). This is because corals rely on light energy for the photoautotrophic carbon production through their dinoflagellate endosymbionts from the genus Symbiodinium (Muscatine and Porter, 1977; Muscatine et al., 1981).

In Symbiodinium, light-harvesting (LH) and photoprotective (PP) pigments form part of the photosynthetic apparatus. The major LH pigments are chlorophyll a (chl a), chlorophyll $\mathrm{c}_{2}$ (chl $c_{2}$ ), and peridinin (per) that build different protein complexes to harvest available light energy (Iglesias-Prieto and Trench, 1997). Diadinoxanthin $(\mathrm{ddx})$ and diatoxanthin $(\mathrm{dtx})$ are components of the xanthophyll cycle in dinoflagellates, and together with $ß$-carotene ( $ß$-car) comprise the PP pigments (Jeffrey and Haxo, 1968; Brown et al., 1999). B-carotene is found in both photosystems together with chl a where it mainly acts as a sink for excess light energy, but also aids in stabilizing the photosystem structure (Kirk, 1994; Frank and Cogdell, 1996; Fromme et al., 2006).

To optimize production rates at differing irradiances, Symbiodinium undergo photoacclimatization of their pigment components. With decreasing light, Symbiodinium harbor more LH pigments, while PP pigment concentrations decrease (Falkowski and Dubinsky, 1981; Dubinsky and Stambler, 2009). The enrichment of LH pigments leads to two potentially cooccurring photoacclimatization processes, namely increases in size and number of photosynthetic units (PSU) (Falkowski and Owens, 1980; Falkowski and Dubinsky, 1981). However, this relationship is not linear as self-shading of light harvesting units eventually leads to decreased photosynthetic efficiency (McCloskey and Muscatine, 1984). Further depth acclimatizations include an increase in photosynthetic efficiency in deeper water (Lesser et al., 2010) and maximum photosynthetic rates at lower irradiances (Falkowski et al., 1990).

Generalist coral species with wide bathymetric distributions, e.g., Stylophora pistillata and Seriatopora hystrix, change their colony morphology in deeper water toward flat shapes with thinner, wider spreading branches in order to decrease self-shading and maximize light capture (Einbinder et al., 2009; Nir et al., 2011). The spacing and size of polyps might also be adjusted, as light exposure is higher in corallites than in coenosarcs tissues (Wangpraseurt et al., 2012). Depth specialist coral genera 
such as Leptoseris have skeletal structures that enable the absorption of more light than shallow water Porites (Kahng et al., 2012). In combination with an arrangement of symbiont cells in a mono-layer, corals of the mesophotic genus Leptoseris maximize light capture and photosynthetic efficiency under low light conditions (Schlichter et al., 1986). Additionally, the association with different symbionts is a factor interacting with depth stratification of certain coral species (Rowan and Knowlton, 1995). For instance, the ability to associate with different Symbiodinium types along light gradients may be a trait of some depth generalist corals broadening their vertical distribution range (Bongaerts et al., 2010). In this regard, some Symbiodinium depth specialist types have been designated because they have only been observed in deep water and low light environments so far. These putative specialist types are C79 in S. pistillata from the southern Great Barrier Reef (Sampayo et al., 2007), type C11, C11N4, C3N5, CN8 in Agaricia on Curacao (Bongaerts et al., 2013), and type C Mcav5 in Montastraea cavernosa in the Bahamas (Lesser et al., 2010). In the case of the coral species Madracis pharensis, a study showed that coral colonies switched from a generalist symbiont type (B7) to a depth specialist (B15) in deeper water (Frade et al., 2008b). The latter symbiont contained more photosynthetic pigments per cell and had different pigment ratios, possibly explaining the superior photophysiological efficiency in its host compared to symbiont-generalist hosting coral species (Frade et al., 2008a). This does not seem to be a universal mechanism though (Cooper et al., 2011; Bongaerts et al., 2013), as generalist symbiont types, like e.g., type C1, can have large bathymetric distributions and are found in shallow and mesophotic coral communities alike (Chan et al., 2009; Cooper et al., 2011). Despite these potentially important mechanisms in depth acclimatization of corals, the interaction of changing Symbiodinium communities and photophysiological capacity are still poorly explored factors as to their role in shaping mesophotic coral communities.

Mesophotic coral ecosystems are receiving increased attention owing to their potential as deep coral refuges in times of global environmental change (see review Lesser et al., 2009; Kahng et al., 2014). Around the Arabian Peninsula, research on mesophotic coral systems has a long tradition, but studies have been geographically limited to the northern Red Sea, i.e., in the Gulf of Aqaba (Fricke and Knauer, 1986; Schlichter et al., 1986; Fricke et al., 1987; Muscatine et al., 1989; Schlichter and Fricke, 1991; Kaiser et al., 1993; Stambler et al., 2008; Alamaru et al., 2009; Einbinder et al., 2009; Mass et al., 2010; Nir et al., 2011). On a global scale, only few studies have investigated the ecophysiology of mesophotic corals under the consideration of the genetic identity of the Symbiodinium community (Lesser et al., 2010; Cooper et al., 2011; Nir et al., 2011). Comprehension of coral functioning over large depth gradients in a holobiont framework is critical to our understanding of the role of mesophotics as potential refuges for shallow-water coral communities. Here, we examined mechanisms of coral holobiont photoacclimatization in the mesophotic central Red Sea through collection of ecological, physiological, and molecular data of coral host and Symbiodinium from the four coral genera Porites, Leptoseris, Pachyseris, and Podabacia.

\section{MATERIALS AND METHODS CORAL COLLECTION}

Corals were sampled in accordance with ethical standards for the care and use of invertebrate animals and KSA Law for Ethics of Research on Living Creatures (National Committee on BioEthics Guidelines as published by King Abdullah Center for Science and Technology). The Saudi Arabian Coastguard Authority issued sailing permits to the sites that include coral collection. Coral fragments were collected using SCUBA and technical diving at the midshore reef Al Fahal (N22 ${ }^{\circ} 15.100$ E038 $\left.{ }^{\circ} 57.382\right)$ in the Saudi Arabian central Red Sea in November 2012. One fragment from the central upward-facing surface per colony of Porites spp., Leptoseris spp., Pachyseris speciosa and Podabacia sp. was taken in $10 \mathrm{~m}$ intervals between 1 and $60 \mathrm{~m}$ (i.e., $1 \mathrm{~m}, 10 \mathrm{~m}, 20 \mathrm{~m}, 30 \mathrm{~m}$, $40 \mathrm{~m}, 50 \mathrm{~m}, 60 \mathrm{~m}$ ). Due to variable vertical distribution, not all corals could be sampled at each depth (see sample distribution in Figure 1).

\section{ENVIRONMENTAL PARAMETERS}

On three days around noon in September 2012, conductivitytemperature-depth (CTD; SBE 16plusV2, Seabird Electronics, USA) and light casts (320-900 nm, Ramses-ACC-VIS, TriOS $\mathrm{GmbH}$, Germany) were performed to $60 \mathrm{~m}$ depth in close proximity to the sampling location measuring photosynthetic active radiation (PAR), spectral irradiance, water temperature, salinity, oxygen saturation, chlorophyll fluorescence, and turbidity approximately every $5 \mathrm{~m}$.

\section{CORAL PROCESSING AND MEASUREMENTS}

Each collected specimen $(n=76)$ was separated in two pieces: one small piece was rinsed with filtered seawater and snapfrozen in liquid nitrogen for subsequent analyses (see below). The remaining bigger fragment was incubated in the dark for approx. 60 min after which maximum quantum yields $\left(\mathrm{F}_{\mathrm{v}} / \mathrm{F}_{\mathrm{m}}\right)$ were measured three times with a Diving Pulse-Amplitude-Modulated (PAM) Fluorometer (Walz, Germany) using default settings.

Coral tissue was removed from snap-frozen pieces with icecold $4 \% \mathrm{NaCl}$ solution using a standard airgun and an airbrush (Airbrush-starter-set, Conrad Electronic SE, Germany) at 6-8 and 2 bar air pressure respectively. After homogenization of tissue, aliquots were taken for Symbiodinium counts, Symbiodinium typing, and protein analysis. The remaining slurry was centrifuged for $5 \mathrm{~min}$ at $3220 \mathrm{~g}$ and the supernatant was removed. The symbiont pellet was washed and resuspended twice before shockfreezing in liquid nitrogen for HPLC analysis of Symbiodinium pigments. All processing steps were conducted on ice. Tissue-less coral skeletons were photographed and their surface area determined using CPCe v4.0 (Kohler and Gill, 2006) against a reference scale, which was placed on each picture.

Symbiodinium densities were determined with six replicate counts in a Neubauer-improved haemocytometer on a light microscope and calculated per coral surface area. The shockfrozen symbiont samples were dried and extracted in $90 \%$ methanol with $1 \mathrm{mM}$ Tris as detailed in Ziegler et al. (2014). Pigment extracts were separated on a reverse-phase HPLC column (18C Chromolith, Merck, Germany) using a linear gradient system with two solvents after Papagiannakis et al. (2005). 


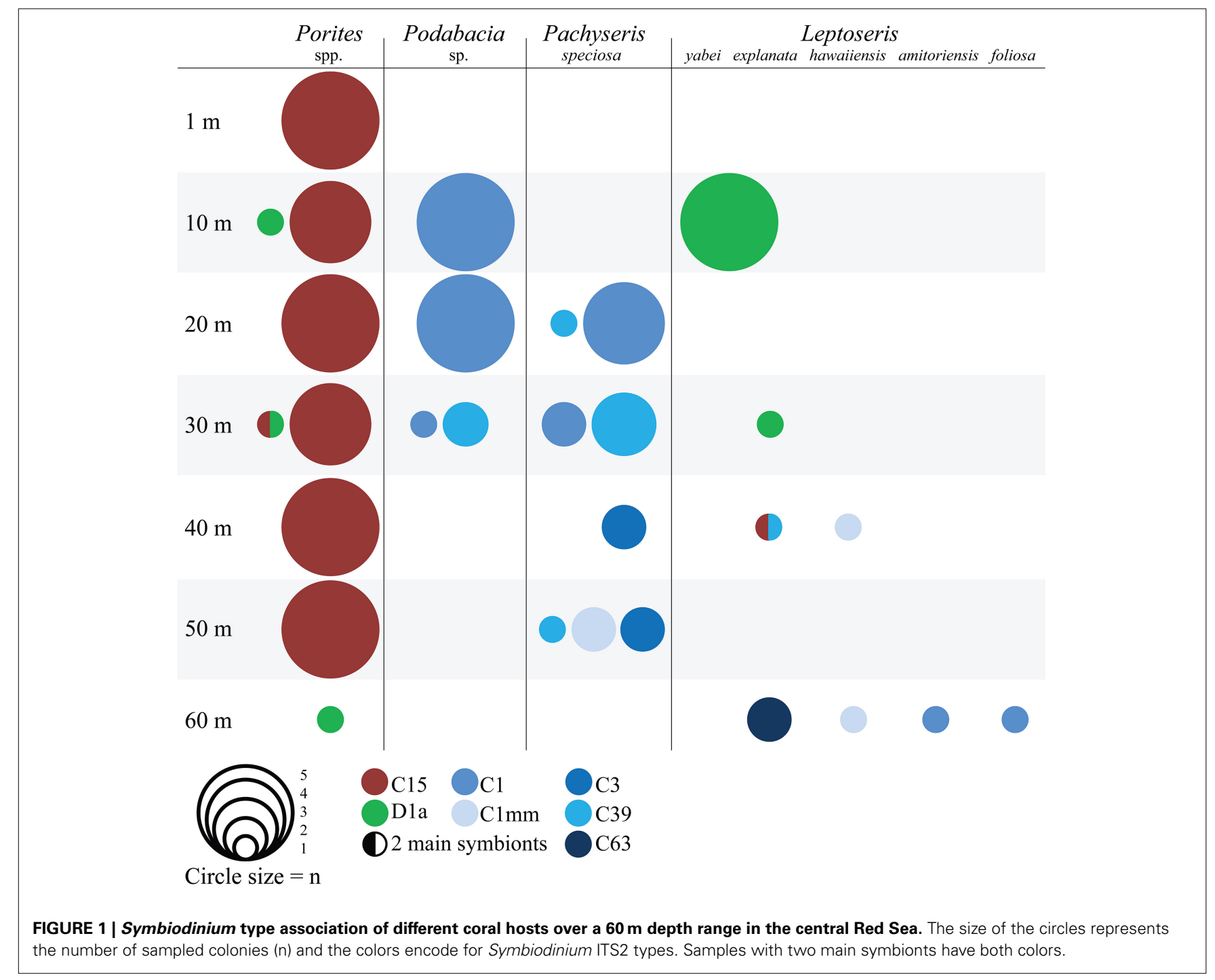

All pigments were measured using a Hitachi L-2455 diode array detector (VWR; Germany) and quantified against pigment standards for chl a and $c_{2}, B$-car, ddx and dtx according to Papagiannakis et al. (2005) and for per (DHI, Denmark) according to Ziegler et al. (2014). The ratio of LH pigments (i.e., chl $\alpha$, chl $c_{2}$, per) to PP pigments (i.e., $B$-car, $\mathrm{ddx}, \mathrm{dtx}$ ), and the xanthophyll de-epoxidation $\left(\mathrm{dtx}(\mathrm{dtx}+\mathrm{ddx})^{-1}\right)$ were calculated.

Total protein content of tissue slurry was determined after Lowry et al. (1951) against a bovine serum albumin standard (DC protein assay, Bio Rad, Germany) with a spectrophotometer (SpectraMax Paradigm, Molecular Devices, USA). Prior to measurement the samples were extracted in $0.5 \mathrm{M} \mathrm{NaOH}$ for $30 \mathrm{~min}$ at $90^{\circ} \mathrm{C}$.

\section{SYMBIODINIUM COMMUNITY COMPOSITION}

Symbiodinium community composition was analyzed via Denaturing Gradient Gel Electrophoresis (DGGE; Cipher DGGE system, CBS Scientific Company, CA) of the ITS2 region. Briefly, DNA was extracted from the tissue slurry using Chelex 100 resin (100-200 mesh, Sigma, USA) and DNA concentrations were determined using the Qbit dsDNA HS Assay kit (Invitrogen, USA). PCR amplification of the symbiont ITS2 region was conducted according to Ziegler et al. (2014) using the forward primer "ITS2intfor" and the reverse primer "ITS2CLAMP" that contains a GC clamp (LaJeunesse and Trench, 2000). PCR products were separated by electrophoresis for $16 \mathrm{~h}$ at $150 \mathrm{~V}$ and $60^{\circ} \mathrm{C}$ on a $8 \%$ polyacrylamide denaturing gradient gel (45-80\% urea-formamide gradient) (LaJeunesse, 2002). Further processing, reamplification, and sequencing was conducted as detailed in Ziegler et al. (2014). Briefly, representative bands were selected for sequencing to determine the ITS2 type of each sample. Chromatograms of the ITS2 sequences were checked, edited manually, and aligned with Geneious 4.8.4, and BLASTed against GenBank nr database for ITS2 type designation and verification of DGGE fingerprints.

\section{STATISTICAL ANALYSES}

Correlation analyses were conducted over depth for physiological parameters. We partitioned the samples by Symbiodinium type association and conducted analyses on three datasets: 1) All 
samples, i.e., the whole data set $(n=76)$, (2) Subset C1 consisting of 24 coral samples from Leptoseris, Pachyseris, and Podabacia, and (3) Subset C15 consisting of 29 Porites samples. Subsets C1 and C15 were selected based on Symbiodinium association of the coral host (harboring Symbiodinium of either type C1 or C15).

Additional analyses were conducted in a comparative coral host-Symbiodinium framework, using the overlapping distribution of Podabacia and Pachyseris hosting Symbiodinium type C1, and Porites hosting Symbiodinium type C15 at 20 and $30 \mathrm{~m}$. Before pooling the samples over depth, Student's $T$-tests were performed to investigate physiological differences between the two depths per species, which showed no significant difference in Porites and Pachyseris. In Podabacia, only one sample from $30 \mathrm{~m}$ was included in the analysis and the respective values were within the range of the samples from $20 \mathrm{~m}$. An analysis of variance (ANOVA) for significant differences between these three hostsymbiont combinations aided the detection of host and symbiont effects. Tukeys' post-hoc comparison was used when appropriate. For some analyses, the assumptions of homogeneity of variance could not be met and a non-parametric Kruskal-Wallis test on ranks was conducted.

To identify combinations of abiotic water parameters that "best explain" the multivariate physiological pattern of the coral samples, a biota-environmental matching (BIOENV) routine was computed with 99 permutations based on Euclidean distances using PRIMER v6 software (Clarke and Gorley, 2006). This analysis maximizes Spearman rank correlations between the resemblance matrices through permutation of all trial variables. Input data were normalized prior to analysis by subtracting the variable's mean from each value and dividing it by the standard deviation using PRIMER normalization option.

\section{RESULTS}

\section{DEPTH STRATIFICATION OF ENVIRONMENTAL PARAMETERS}

Light intensity decreased exponentially with depth. While $1200 \mu \mathrm{mol}$ photons $\mathrm{m}^{-2} \mathrm{~s}^{-1}$ reached to just below the surface at noon, only $1 \%$ of this light reached $60 \mathrm{~m}$ depth. Hyperspectral scans revealed a strong wavelength specific extinction with water depth (Figure 2A). Water temperature decreased from $30.5^{\circ} \mathrm{C}$ at the surface to $25.5^{\circ} \mathrm{C}$ at $60 \mathrm{~m}$. Oxygen saturation decreased from $93 \%$ to $77 \%$ and chlorophyll increased from $0.08 \mathrm{mg} \mathrm{m}^{-3}$ to $1.0 \mathrm{mg} \mathrm{m}^{-3}$ from the surface to $60 \mathrm{~m}$ (Figure 2B). Turbidity (NTU $0.12 \pm 0.02 \mathrm{SD}$ ) and salinity (PSU $39.42 \pm 0.14$ SD) remained stable over the depth gradient (not shown). Analyses applying the BIOENV routine identified light intensity as the variable best explaining the multivariate pattern of the physiological dataset (described below) on its own $(r=0.177, p=$ 0.03 ). Next best were combinations of a second explanatory variable with light intensity (light + temperature $r=0.149$; light + chlorophyll $r=0.133$ ). As explanatory variables, salinity, turbidity, and oxygen saturation were of minor importance.

\section{CORAL-SYMBIODINIUM ASSOCIATION OVER DEPTH}

Analysis of Symbiodinium associated with coral samples revealed five distinct ITS2 sequences of known types (C1, C3, C15, C39, D1a), and 2 novel sequences (type C1mm: GenBank Accession Number [ACN] KJ493788, type C63: ACN KJ493789). Both novel ITS2 sequences had high sequence similarity to Symbiodinium goreaui (type C1: ACN AF333515, LaJeunesse, 2001). Additionally, DGGE profiles of these samples faintly contained the original S. goreaui C1 band and vice versa (Figure 3), and it is likely that $\mathrm{C} 1$ represents an intra-genomic variant of the ITS2 rDNA of these novel symbiont types (Thornhill et al., 2007),

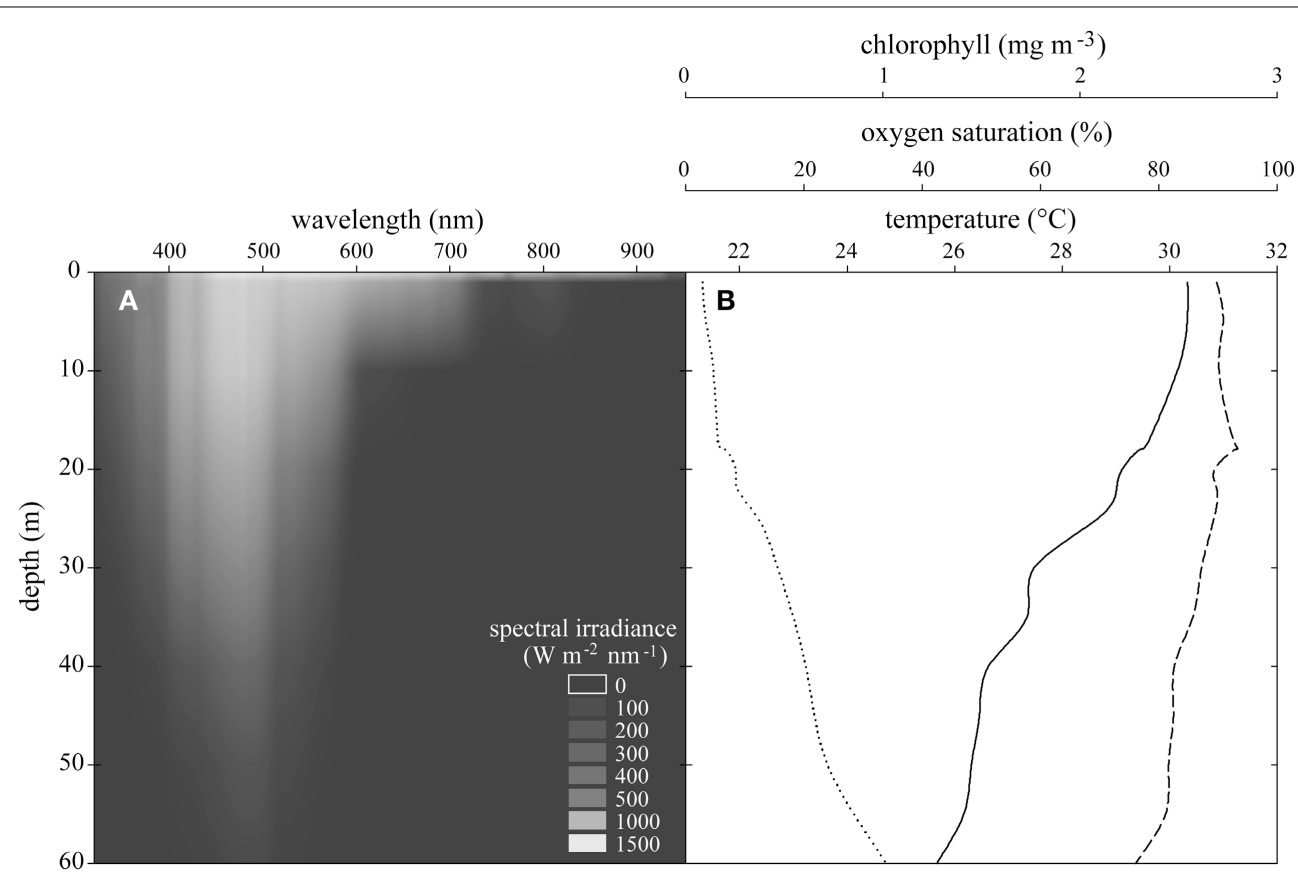

FIGURE 2 | (A) Spectral irradiance at each wavelength over experimental depths. (B) Means of CTD casts of temperature (solid line), oxygen saturation (dashed line), and chlorophyll concentration (dotted line) between 0 and $60 \mathrm{~m}$ in the Saudi Arabian central Red Sea. 


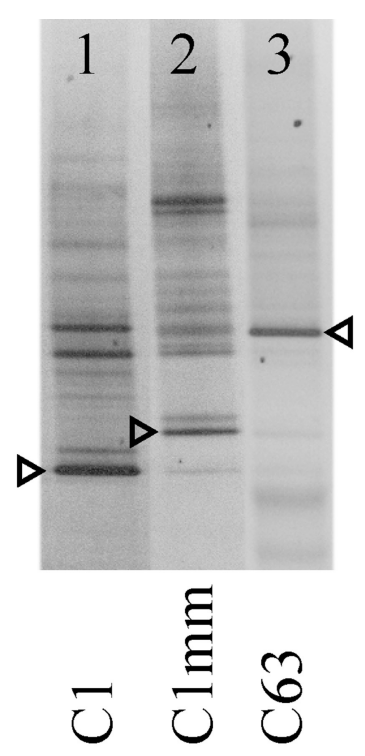

FIGURE 3 | Negative image of novel Symbiodinium ITS2 DGGE profiles from selected coral samples. Arrows indicate excised and sequenced bands. Designated symbiont types are indicated at the bottom of the gel.

suggesting the conversion from a genome dominated by the ITS2 C1 sequence to ones with derived sequences (LaJeunesse, 2005; Lajeunesse and Thornhill, 2011; Thornhill et al., 2014). Yet the novel types, C1mm and C63, exhibited distinct DGGE profiles (Figure 3).

Host-symbiont relationships followed a coral specific pattern (Figure 1): most Porites samples harbored Symbiodinium type C15 and three colonies harbored type D1a. In Pachyseris and Podabacia the most common Symbiodinium were the widely distributed type $\mathrm{C} 1$ and $\mathrm{C} 39$, which is identical to $\mathrm{C} 1$ with the exception of a 14-base pair deletion. Furthermore, at 40 and $50 \mathrm{~m}$ Pachyseris associated with Symbiodinium types C3 and C1mm. The different species of Leptoseris associated with Symbiodinium types D1a (L. yabei, L. explanata), C1 (L. amitoriensis, L. foliosa), C1mm (L. hawaiiensis), and C15, C39, C63 (all L. explanata).

\section{SYMBIODINIUM TYPE DIFFERENCES, DEPTH ACCLIMATIZATION, AND HOST EFFECT}

We collected a range of physiological parameters for four coral genera over depth profiles from 1 to $60 \mathrm{~m}$ in order to comprehend how depth relates to differences in physiology (Figure 4). To identify which physiological parameters varied over depths, we tested for correlations of physiological parameters to depth considering either all samples $(n=76)$, subset C1 $(n=24$ from Leptoseris, Pachyseris, and Podabacia), or subset C15 ( $n=29$ from Porites) (Table 1). Taking samples from all coral species into account, symbiont cell densities, total protein content, and PP/LH ratios all significantly decreased over water depth, whereas $\mathrm{F}_{\mathrm{v}} / \mathrm{F}_{\mathrm{m}}$, cellular chl a content, and $B$-carotene chl $\mathrm{a}^{-1}$ increased. Other pigment to chl a ratios and the xanthophyll de-epoxidation were not significantly correlated with depth (Table 1). Considering only coral samples with either Symbiodinium C1 or Symbiodinium
C15 revealed that some traits differed between Symbiodinium types. For instance, Symbiodinium C15 had higher xanthophyll de-epoxidation rates than $\mathrm{C} 1$ and overall, maximum quantum yields were lower in C15 than in all other symbionts (Figure 4). Further, depth-dependent differences between these Symbiodinium types were apparent for some parameters: in corals harboring Symbiodinium type $\mathrm{C} 15$ there was a significant negative correlation between $\mathrm{ddx}$ chl $\mathrm{a}^{-1}$ ratio and depth, and $\mathrm{F}_{\mathrm{v}} / \mathrm{F}_{\mathrm{m}}$ significantly increased with depth, while analyses for corals hosting Symbiodinium $\mathrm{C} 1$ revealed weak and insignificant correlations for these parameters (Table 1). In contrast, in corals associated with Symbiodinium type $\mathrm{C} 1$ xanthophyll de-epoxidation and depth were positively correlated, while they were independent in corals hosting type C15 (Table 1).

Next we wanted to understand how physiology differs between coral species that host the same main Symbiodinium type. Podabacia and Pachyseris had overlapping distributions at 20 and $30 \mathrm{~m}$ and both hosted Symbiodinium type C1 (Figure 1). A comparison between C1-hosting Podabacia and Pachyseris and C15-hosting Porites at 20 and $30 \mathrm{~m}$ indicated a significant coral host effect (Figure 5, Supplementary Table 1). Podabacia contained significantly more protein than any other coral genus, and at 20 and $30 \mathrm{~m}$ symbiont cell densities in Podabacia were also higher than in Pachyseris and Porites (Figure 5). Further, coral host association had a significant effect on photosynthetic pigments. The cellular chl a concentration and the B-carotene chl $\mathrm{a}^{-1}$ ratio were significantly reduced in Symbiodinium type $\mathrm{C} 1$ in Podabacia in comparison to Pachyseris and Porites. Conversely, Symbiodinium type $\mathrm{C} 1$ in Podabacia contained significantly more peridinin $\mathrm{chl}^{-1}$ and diadinoxanthin $\mathrm{chl}^{-1}$ than Symbiodinium type C1 in Pachyseris and C15 Porites (Figure 5). Consequently, the PP/LH ratio was increased in Podabacia compared to Pachyeris and Porites, but this difference was not significant in the nonparametric test on ranks (Supplementary Table 1).

\section{DISCUSSION}

\section{COMMON CHARACTERISTICS IN CORAL DEPTH ACCLIMATIZATION}

Light availability was exponentially decreasing over the $60 \mathrm{~m}$ depth gradient, and it was the best abiotic explanatory variable for changes in holobiont physiology. In comparison, temperature, fluorescence, and oxygen saturation were of minor importance, although their influence on physiological processes cannot be ruled out. Some general trends of light acclimatization could be observed for all central Red Sea corals, and these trends were similar to those reported from studies conducted in other oceans. For instance, the decrease in symbiont cell densities and increase in chl a was comparable to that of other corals over similar depth gradients (Frade et al., 2008a; Cooper et al., 2011), and data from the deep mesophotic Red Sea suggest that the trend continues until corals become azooxanthellate (Fricke et al., 1987; Kaiser et al., 1993).

The ratios of the other pigments to chl a can be modulated to enhance photosynthetic efficiency when light becomes limited (Iglesias-Prieto and Trench, 1994, 1997). We found decreasing $\mathrm{PP} / \mathrm{LH}$ ratios with depth and this indicates photoacclimatization to low light (Falkowski and Dubinsky, 1981; Dubinsky and Stambler, 2009). Furthermore, the positive correlation of B-car 


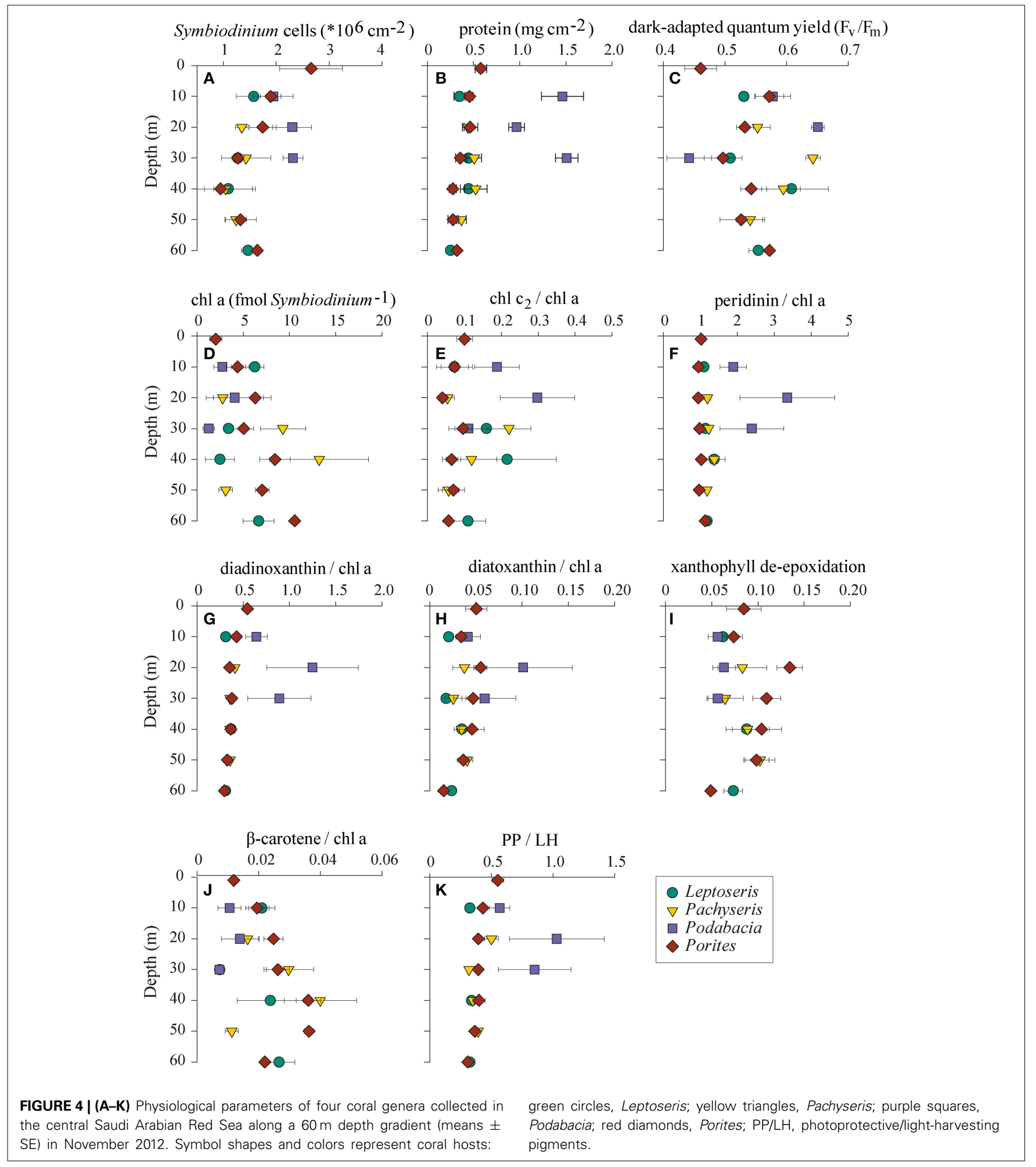

to chl a with depth suggests that increasing photosynthetic efficiency in deeper water was facilitated by an increased number of PSUs (MacIntyre et al., 2002). However, in contrast to previous studies over mesophotic gradients, here ratios of $\mathrm{chl}_{2}$ and per to chl a were not correlated with depth, indicating stable PSU sizes (Kaiser et al., 1993; Lesser et al., 2010; Nir et al., 2011), although we cannot exclude that intra-colony differences at other sites of a given colony exist.

\section{CORAL-SYMBIODINIUM DEPTH STRUCTURE AND PARTITIONING}

Coral-Symbiodinium association on the upward-facing surface of the colonies followed a host-specific rather than a depth-specific 
pattern supporting data from the Great Barrier Reef (Bongaerts et al., 2011) and the Caribbean (Bongaerts et al., 2013). Although one species of Leptoseris hosted clade D symbionts in shallow water and other corals of this genus were associated with clade $\mathrm{C}$ symbionts in deep water, there was no symbiont species overlap between depths, and hence we could not identify depthdependent shifts of the main Symbiodinium types as reported for other coral species (Frade et al., 2008b; Lesser et al., 2010; Cooper et al., 2011).

Table 1 | Correlation between physiological parameters and depth for three sets of samples: all samples $(n=76)$, subset $C 1(n=24)$, subset C15 $(n=29)$.

\section{Coral holobiont physiology}

Correlation ( $r$ ) with depth in sample subsets

\begin{tabular}{|c|c|c|c|}
\hline & \\
\hline & all samples & C1 & C15 \\
\hline Symbiodinium cells $\left(10^{6} \mathrm{~cm}^{-2}\right)$ & -0.49 & -0.45 & -0.69 \\
\hline Protein $\left(\mathrm{mg} \mathrm{cm}^{-2}\right)$ & -0.40 & -0.73 & -0.68 \\
\hline $\mathrm{PP} \mathrm{LH}^{-1}$ & -0.23 & -0.35 & -0.60 \\
\hline $\mathrm{F}_{\mathrm{v}} / \mathrm{F}_{\mathrm{m}}$ & 0.10 & -0.26 & 0.24 \\
\hline chl a (fmol Symbiodinium ${ }^{-1}$ ) & 0.34 & 0.42 & 0.63 \\
\hline ß-carotene chl $\mathrm{a}^{-1}$ & 0.36 & 0.55 & 0.79 \\
\hline Diadinoxanthin chl a ${ }^{-1}$ & -0.22 & -0.35 & -0.74 \\
\hline Diatoxanthin chl a $a^{-1}$ & -0.14 & -0.21 & -0.26 \\
\hline $\operatorname{chl} c_{2} \operatorname{chl~} a^{-1}$ & -0.10 & -0.29 & -0.13 \\
\hline Peridinin chl $a^{-1}$ & -0.10 & -0.31 & 0.13 \\
\hline Xanthophyll de-epoxidation & 0.06 & 0.43 & 0.02 \\
\hline
\end{tabular}

Significant correlations $(p<0.05)$ in bold.
Symbiodinium type C15 is the most common type in the genus Porites in the Red Sea and Western Indian Ocean (LaJeunesse, 2005; Barshis et al., 2010), and our study extends the codistribution of Porites with C15 into the mesophotics (LaJeunesse, 2005). Further, these findings underline the relative specificity of Porites species with clade $\mathrm{C}$ in the Indo-Pacific (LaJeunesse et al., 2008; Silverstein et al., 2012). In the Persian Gulf, Porites is associated with C3 (Hume et al., 2013). C3 represents another generalist symbiont type in Indo-Pacific reefs (LaJeunesse et al., 2003, 2004), which we encountered twice in deep-dwelling colonies of Pachyseris, but not in Porites. Symbiodinium C39 from Pachyseris and Podabacia in this study has previously been identified as a locally prevalent symbiont in Mussidae and Diploastrea in the Red Sea (LaJeunesse, 2005).

Our data suggest that photosynthetic properties of Symbiodinium play a role in the vertical distribution range of their coral host. For instance, the higher PP xanthophyll de-epoxidation in Symbiodinium type C15 may facilitate the occurrence of Porites even in very shallow water where they are exposed to light intensities that can potentially impair the photosynthetic apparatus (Brown et al., 1999). This advantage may offset the overall lower maximum photosynthetic yield of Symbiodinium type C15. Porites has a broad bathymetric distribution and this is reflected by Symbiodinium type C15 that showed a strong photoacclimatory signal. For instance, a negative correlation of $\mathrm{ddx}$ to chl a with depth indicates that PP pathways are downregulated when light is scarce (Frank and Cogdell, 1996; Brown et al., 1999). At the same time, the LH potential in deeper water was increased by harboring more cellular chl a along with increasing $B$-carotene to chl a ratios (MacIntyre et al., 2002). Although Symbiodinium type C1 has been found to be
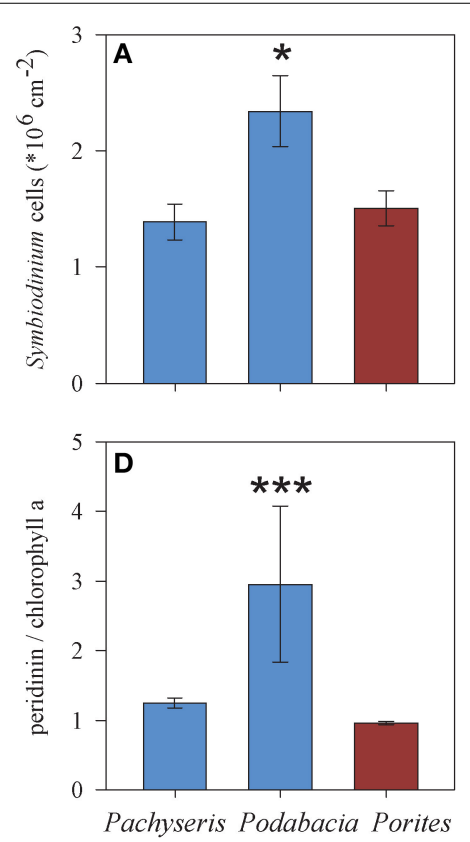

FIGURE 5 | Comparison of physiological parameters (A-F) between the corals Podabacia and Pachyseris (both hosting Symbiodinium type C1) and Porites (hosting Symbiodinium C15) for samples from
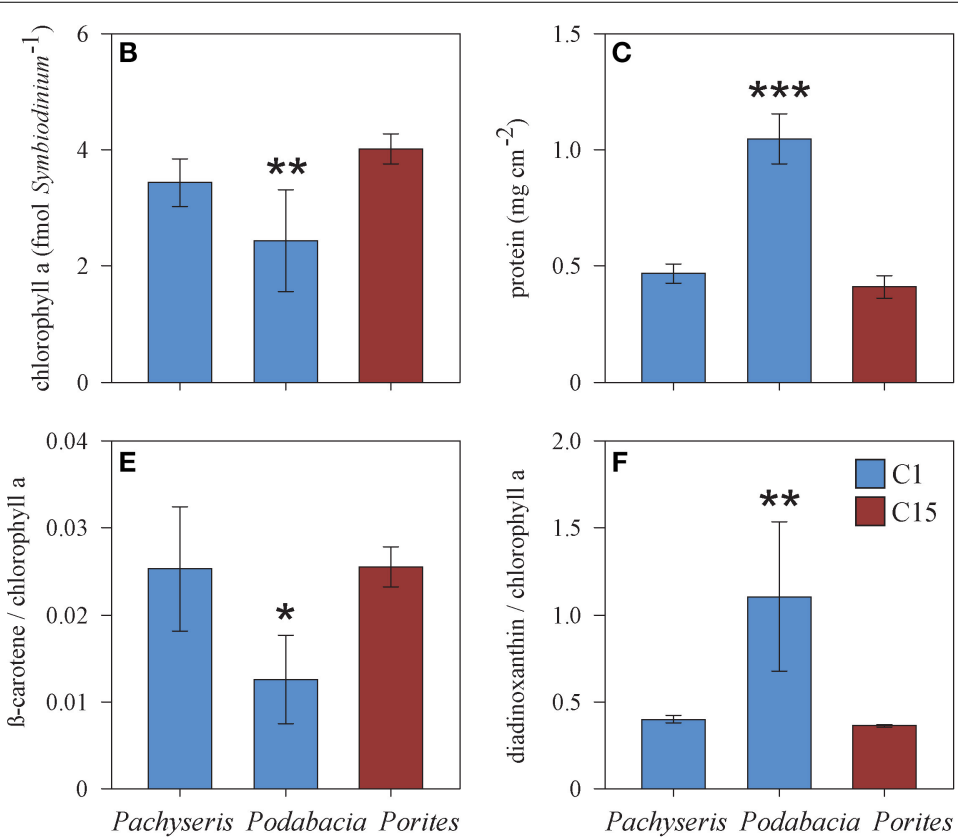

20 and $\mathbf{3 0} \mathrm{m}$ (means $\pm \mathrm{SE}$ ). Significant differences (ANOVA or Kruskal-Wallis test) marked by asterisks: ${ }^{*} p<0.05,{ }^{* *} p<0.01$, *** $p<0.001$. 
associated with their coral host over large (mesophotic) depths ranges in other locations (Chan et al., 2009; Cooper et al., 2011), all corals associated with Symbiodinium type $\mathrm{C} 1$ in this study demonstrated limited vertical distributions and only weak or no photoacclimatory signals.

We did not observe a depth-specialist Symbiodinium type, but the details of the observed host-Symbiodinium associations suggest an influence of the host species on the physiology of its symbiont. Our data show that the coral host had a significant effect on the photosynthetic pigments of Symbiodinium. For instance, Symbiodinium type C1 in Podabacia had two- to threefold higher per to chl a ratios and two-fold higher ddx to chl a ratios. In contrast, $B$-carotene to chl a ratios were decreased and Symbiodinium type C1 in Podabacia contained significantly less chl a than Symbiodinium type C1 in Pachyseris. Podabacia also contained higher densities of Symbiodinium cells and protein in its tissues per coral surface area, indicating high tissue biomass (Stimson et al., 2002). Taken together this suggests Symbiodinium type C1 in Podabacia occur in higher densities and consequently store less accessory chl a, while light capture is optimized through larger LH antennae (Hofmann et al., 1996; Iglesias-Prieto and Trench, 1997). On the other hand, the physiology of the distinct Symbiodinium -types in the two host species Porites and Pachyseris was highly similar to each other, indicating the same "physiological strategy" was employed despite different host and symbiont environments. The direct influence of different coral species on photosystem structure in the same Symbiodinium type expands previous findings by Krämer et al. (2013) who found varying PP pigment capacity in the same Symbiodinium type hosted by different coral species. As in our study, tissue biomass was different between coral species and Krämer et al. (2013) conclude that these differences exert an influence on the internal light regime for Symbiodinium, because host tissue thickness determines light absorption (Dimond et al., 2012). Another notion that may explain the observed coral host effect could lie in the hyperdiversity of LH protein-encoding genes that have been revealed in genomic surveys of Symbiodinium (Reichman et al., 2003; Boldt et al., 2012). Differential expression of these and other photosynthesis genes is generally possible (Baumgarten et al., 2013), but its interaction with coral host factors has not been tested. Finally, it cannot be ruled out that host specific physiological differences in Symbiodinium $\mathrm{C} 1$ may be attributed to fine-scale genetic divergence not resolved by the ITS2 marker, which has previously been demonstrated for Symbiodinium B1 (Santos et al., 2004), C3 (Thornhill et al., 2014), and to a much lesser extent for C1 (Thornhill et al., 2014).

Taken together, our data support a view that acclimatization of corals over depth is at least partially facilitated by Symbiodinium physiology. The symbiont physiology (e.g., Symbiodinium pigment composition and cell densities) in turn is host-specific as highlighted by comparative analysis of different coral species harboring the same main Symbiodinium type. This underlines the importance of studying interactions of coral hosts and Symbiodinium types as drivers of acclimatization in order to gain further insight into the ecology of mesophotic coral communities. Increasing our understanding of the biology of mesophotic corals is important to better comprehend their potential role as coral refuges in regard to global environmental change.

\section{ACKNOWLEDGMENTS}

We thank KAUST CMOR staff and boat crews for their support in the field, in particular C. Walcher, D. Pallett, T. Sinclair-Taylor, T. Habis and F. Mallon. We are grateful to A. Baird for assistance in taxonomic assignment of the coral species, T. LaJeunesse for advice on DGGE interpretation, X. Gong for his assistance in the lab, and the reviewers for their comments on the manuscript. Maren Ziegler was financially supported by a DAAD postgraduate research fellowship. Remaining financial support was provided by KAUST baseline funds to Christian R. Voolstra.

\section{SUPPLEMENTARY MATERIAL}

The Supplementary Material for this article can be found online at: http://www.frontiersin.org/journal/10.3389/fmars.2015. 00004/abstract

\section{REFERENCES}

Alamaru, A., Loya, Y., Brokovich, E., Yam, R., and Shemesh, A. (2009). Carbon and nitrogen utilization in two species of Red Sea corals along a depth gradient: insights from stable isotope analysis of total organic material and lipids. Geochim. Cosmochim. Acta 73, 5333-5342. doi: 10.1016/j.gca.2009.06.018

Barshis, D. J., Stillman, J. H., Gates, R. D., Toonen, R. J., Smith, L. W., and Birkeland, C. (2010). Protein expression and genetic structure of the coral Porites lobata in an environmentally extreme Samoan back reef: does host genotype limit phenotypic plasticity? Mol. Ecol. 19, 1705-1720. doi: 10.1111/j.1365294X.2010.04574.x

Baumgarten, S., Bayer, T., Aranda, M., Liew, Y., Carr, A., Micklem, G., et al. (2013). Integrating microRNA and mRNA expression profiling in Symbiodinium microadriaticum, a dinoflagellate symbiont of reef-building corals. BMC Genomics 14:704. doi: 10.1186/1471-2164-14-704

Boldt, L., Yellowlees, D., and Leggat, W. (2012). Hyperdiversity of genes encoding integral light-harvesting proteins in the dinoflagellate Symbiodinium sp. PLoS ONE 7:e47456. doi: 10.1371/journal.pone.0047456

Bongaerts, P., Frade, P., Ogier, J., Hay, K., Van Bleijswijk, J., Englebert, N., et al. (2013). Sharing the slope: depth partitioning of agariciid corals and associated Symbiodinium across shallow and mesophotic habitats $(2-60 \mathrm{~m})$ on a Caribbean reef. BMC Evol. Biol. 13:205. doi: 10.1186/1471-2148-13-205

Bongaerts, P., Riginos, C., Ridgway, T., Sampayo, E. M., Van Oppen, M. J. H., Englebert, N., et al. (2010). Genetic divergence across habitats in the widespread coral Seriatopora hystrix and its associated Symbiodinium. PLoS ONE 5:e10871. doi: 10.1371/journal.pone.0010871

Bongaerts, P., Sampayo, E. M., Bridge, T. C. L., Ridgway, T., Vermeulen, F., Englebert, N., et al. (2011). Symbiodinium diversity in mesophotic coral communities on the Great Barrier Reef: a first assessment. Mar. Ecol. Prog. Ser. 439, 117-126. doi: 10.3354/meps09315

Brown, B. E., Ambarsari, I., Warner, M. E., Fitt, W. K., Dunne, R. P., Gibb, S. W., et al. (1999). Diurnal changes in photochemical efficiency and xanthophyll concentrations in shallow water reef corals: evidence for photoinhibition and photoprotection. Coral Reefs 18, 99-105. doi: 10.1007/s003380050163

Chan, Y., Pochon, X., Fisher, M., Wagner, D., Concepcion, G., Kahng, S., et al. (2009). Generalist dinoflagellate endosymbionts and host genotype diversity detected from mesophotic (67-100 m depths) coral Leptoseris. BMC Ecol. 9:21. doi: 10.1186/1472-6785-9-21

Clarke, K., and Gorley, R. (2006). PRIMER v6: User Manual/Tutorial. Plymouth: PRIMER-E.

Cooper, T. F., Ulstrup, K. E., Dandan, S. S., Heyward, A. J., Kuhl, M., Muirhead, A., et al. (2011). Niche specialization of reef-building corals in the mesophotic zone: metabolic trade-offs between divergent Symbiodinium types. Proc. R. Soc. B Biol. Sci. 278, 1840-1850. doi: 10.1098/rspb.2010.2321

Dimond, J. L., Holzman, B. J., and Bingham, B. L. (2012). Thicker host tissues moderate light stress in a cnidarian endosymbiont. J. Exp. Biol. 215, 2247-2254. doi: $10.1242 /$ jeb.067991 
Dubinsky, Z., Falkowski, P. G., Porter, J. W., and Muscatine, L. (1984). Absorption and utilization of radiant energy by light- and shade-adapted colonies of the hermatypic coral Stylophora pistillata. Proc. R. Soc. Lond. Ser. B. Biol. Sci. 222, 203-214. doi: 10.1098/rspb.1984.0059

Dubinsky, Z., and Stambler, N. (2009). Photoacclimation processes in phytoplankton: mechanisms, consequences, and applications. Aquat. Microb. Ecol. 56, 163-176. doi: 10.3354/ame01345

Einbinder, S., Mass, T., Brokovich, E., Dubinsky, Z., Erez, J., and Tchernov, D. (2009). Changes in morphology and diet of the coral Stylophora pistillata along a depth gradient. Mar. Ecol. Prog. Ser. 381, 167-174. doi: 10.3354/meps07908

Falkowski, P. G., and Dubinsky, Z. (1981). Light-shade adaptation of Stylophora pistillata, a hermatypic coral from the Gulf of Eilat. Nature 289, 172-174. doi: 10.1038/289172a0

Falkowski, P. G., Jokiel, P. L., and Kinzie, R. A. (1990). "Irradiance and corals”, in Ecosystems of the World. 25. Coral Reefs, ed Z. Dubinsky (Amsterdam: Elsevier), 89-108.

Falkowski, P. G., and Owens, T. G. (1980). Light: shade adaptation: two strategies in marine phytoplankton. Plant Physiol. 66, 592-595. doi: 10.1104/pp.66.4.592

Frade, P. R., Bongaerts, P., Winkelhagen, A. J. S., Tonk, L., and Bak, R. P. M. (2008a). In situ photobiology of corals over large depth ranges: a multivariate analysis on the roles of environment, host, and algal symbiont. Limnol. Oceanogr. 53, 2711-2723. doi: 10.4319/lo.2008.53.6.2711

Frade, P. R., De Jongh, F., Vermeulen, F., Van Bleijswijk, J., and Bak, R. P. M. (2008b). Variation in symbiont distribution between closely related coral species over large depth ranges. Mol. Ecol. 17, 691-703. doi: 10.1111/j.1365294X.2007.03612.x

Frank, H. A., and Cogdell, R. J. (1996). Carotenoids in photosynthesis. Photochem. Photobiol. 63, 257-264. doi: 10.1111/j.1751-1097.1996.tb03022.x

Fricke, H. W., and Knauer, B. (1986). Diversity and spatial pattern of coral communities in the Red Sea upper twilight zone. Oecologia 71, 29-37. doi: 10.1007/BF00377316

Fricke, H. W., Vareschi, E., and Schlichter, D. (1987). Photoecology of the coral Leptoseris fragilis in the Red Sea twilight zone (an experimental study by submersible). Oecologia 73, 371-381. doi: 10.1007/BF00385253

Fromme, P., Yu, H., Deruyter, Y. S., Jolley, C., Chauhan, D. K., Melkozernov, A., et al. (2006). Structure of photosystems I and II. C. R. Chim. 9, 188-200. doi: 10.1016/j.crci.2005.06.039

Hofmann, E., Wrench, P. M., Sharples, F. P., Hiller, R. G., Welte, W., and Diederichs, K. (1996). Structural basis of light harvesting by carotenoids: peridininchlorophyll-protein from Amphidinium carterae. Science 272, 1788-1791. doi: 10.1126/science.272.5269.1788

Hume, B., D’angelo, C., Burt, J., Baker, A. C., Riegl, B., and Wiedenmann, J. (2013). Corals from the Persian/Arabian Gulf as models for thermotolerant reef-builders: prevalence of clade C3 Symbiodinium, host fluorescence and ex situ temperature tolerance. Mar. Pollut. Bull. 72, 313-322. doi: 10.1016/j.marpolbul.2012.11.032

Iglesias-Prieto, R., and Trench, R. K. (1994). Acclimation and adaptation to irradiance in symbiotic dinoflagellates. I. Responses of the photosynthetic unit to changes in photon flux-density. Mar. Ecol. Prog. Ser. 113, 163-175. doi: $10.3354 /$ meps 113163

Iglesias-Prieto, R., and Trench, R. K. (1997). Acclimation and adaptation to irradiance in symbiotic dinoflagellates. II. Response of chlorophyll-protein complexes to different photon-flux densities. Mar. Biol. 130, 23-33. doi: $10.1007 / \mathrm{s} 002270050221$

Jeffrey, S. W., and Haxo, F. T. (1968). Photosynthetic pigments of symbiotic dinoflagellates (zooxanthellae) from corals and clams. Biol. Bull. 135, 149-165. doi: $10.2307 / 1539622$

Kahng, S. E., Copus, J. M., and Wagner, D. (2014). Recent advances in the ecology of mesophotic coral ecosystems (MCEs). Curr. Opin. Environ. Sustainability 7, 72-81. doi: 10.1016/j.cosust.2013.11.019

Kahng, S. E., Garcia-Sais, J. R., Spalding, H. L., Brokovich, E., Wagner, D., Weil, E., et al. (2010). Community ecology of mesophotic coral reef ecosystems. Coral Reefs 29, 255-275. doi: 10.1007/s00338-010-0593-6

Kahng, S. E., Hochberg, E. J., Apprill, A., Wagner, D., Luck, D. G., Perez, D., et al. (2012). Efficient light harvesting in deep-water zooxanthellate corals. Mar. Ecol. Prog. Ser. 455, 65-77. doi: 10.3354/meps09657

Kaiser, P., Schlichter, D., and Fricke, H. W. (1993). Influence of light on algal symbionts of the deep water coral Leptoseris fragilis. Mar. Biol. 117, 45-52. doi: 10.1007/BF00346424
Kirk, J. T. O. (1994). Light and Photosynthesis in Aquatic Environments. Cambridge: Cambridge Universtity Press. doi: 10.1017/CBO9780511623370

Kohler, K. E., and Gill, S. M. (2006). Coral point count with excel extensions (CPCe): a visual basic program for the determination of coral and substrate coverage using random point count methodology. Computat. Geosci. 32, 1259-1269. doi: 10.1016/j.cageo.2005.11.009

Krämer, W. E., Schrameyer, V., Hill, R., Ralph, P. J., and Bischof, K. (2013). PSII activity and pigment dynamics of Symbiodinium in two Indo-Pacific corals exposed to short-term high-light stress. Mar. Biol. 160, 563-577. doi: 10.1007/s00227-012-2113-4

LaJeunesse, T. C. (2001). Investigating the biodiversity, ecology and phylogeny of endosymbiontic dinoflagellates in the genus Symbiodinium using the ITS region: in search of a "species" level marker. J. Phycol. 37, 866-880. doi: 10.1046/j.1529-8817.2001.01031.x

LaJeunesse, T. C. (2002). Diversity and community structure of symbiotic dinoflagellates from Caribbean coral reefs. Mar. Biol. 141, 387-400. doi: 10.1007/s00227002-0829-2

LaJeunesse, T. C. (2005). "Species" radiations of symbiotic dinoflagellates in the Atlantic and Indo-Pacific since the miocene-pliocene transition. Mol. Biol. Evol. 22, 570-581. doi: 10.1093/molbev/msi042

LaJeunesse, T. C., Bhagooli, R., Hidaka, M., Devantier, L., Done, T., Schmidt, G. W., et al. (2004). Closely related Symbiodinium spp. differ in relative dominance in coral reef host communities across environmental, latitudinal and biogeographic gradients. Mar. Ecol. Prog. Ser. 284, 147-161. doi: 10.3354/meps 284147

LaJeunesse, T. C., Bonilla, H. R., Warner, M. E., Wills, M., Schmidt, G. W., and Fitt, W. K. (2008). Specificity and stability in high latitude eastern Pacific coral-algal symbioses. Limnol. Oceanogr. 53, 719-727. doi: 10.4319/lo.2008.53.2.0719

LaJeunesse, T. C., Loh, W. K. W., Van Woesik, R., Hoegh-Guldberg, O., Schmidt, G. W., and Fitt, W. K. (2003). Low symbiont diversity in southern Great Barrier Reef corals, relative to those of the Caribbean. Limnol. Oceanogr. 48, 2046-2054. doi: 10.4319/lo.2003.48.5.2046

Lajeunesse, T. C., and Thornhill, D. J. (2011). Improved resolution of reefcoral endosymbiont (Symbiodinium) species diversity, ecology, and evolution through psbA non-coding region genotyping. PLOS ONE 6:e29013. doi: 10.1371/journal.pone.0029013

LaJeunesse, T. C., and Trench, R. K. (2000). Biogeography of two species of Symbiodinium (Freudenthal) inhabiting the intertidal sea anemone Anthopleura elegantissima (Brandt). Biol. Bull. 199, 126-134. doi: 10.2307/1542872

Lesser, M. P., Slattery, M., and Leichter, J. J. (2009). Ecology of mesophotic coral reefs. J. Exp. Mar. Biol. Ecol. 375, 1-8. doi: 10.1016/j.jembe.2009.05.009

Lesser, M. P., Slattery, M., Stat, M., Ojimi, M., Gates, R. D., and Grottoli, A. (2010). Photoacclimatization by the coral Montastraea cavernosa in the mesophotic zone: light, food, and genetics. Ecology 91, 990-1003. doi: 10.1890/09-0313.1

Lowry, O., Rosebrough, N., Farr, A., and Randall, R. (1951). Protein measurement with the Folin phenol reagent. J. Biol. Chem. 193, 265-275.

MacIntyre, H. L., Kana, T. M., Anning, T., and Geider, R. J. (2002). Photoacclimation of photosynthesis irradiance response curves and photosynthetic pigments in microalgae and cyanobacteria. J. Phycol. 38, 17-38. doi: 10.1046/j.1529-8817.2002.00094.x

Mass, T., Kline, D. I., Roopin, M., Veal, C. J., Cohen, S., Iluz, D., et al. (2010). The spectral quality of light is a key driver of photosynthesis and photoadaptation in Stylophora pistillata colonies from different depths in the Red Sea. J. Exp. Biol. 213, 4084-4091. doi: 10.1242/jeb.039891

McCloskey, L. R., and Muscatine, L. (1984). Production and respiration in the Red Sea coral Stylophora pistillata as a function of depth. Proc. R. Soc. Lond. Ser. B Biol. Sci. 222, 215-230. doi: 10.1098/rspb.1984.0060

Muscatine, L., Mccloskey, L. R., and Marian, R. E. (1981). Estimating the daily contribution of carbon from zooxanthellae to coral animal respiration. Limnol. Oceanogr. 26, 601-611. doi: 10.4319/lo.1981.26.4.0601

Muscatine, L., and Porter, J. W. (1977). Reef corals: mutualistic symbioses adapted to nutrient-poor environments. Bioscience 27, 454-460. doi: 10.2307/1297526

Muscatine, L., Porter, J. W., and Kaplan, I. R. (1989). Resource partitioning by reef corals as determined from stable isotope composition. Mar. Biol. 100, 185-193. doi: 10.1007/BF00391957

Nir, O., Gruber, D. F., Einbinder, S., Kark, S., and Tchernov, D. (2011). Changes in scleractinian coral Seriatopora hystrix morphology and its endocellular Symbiodinium characteristics along a bathymetric gradient from shallow to mesophotic reef. Coral Reefs 30, 1089-1100. doi: 10.1007/s00338-011-0801-z 
Papagiannakis, E., Van Stokkum, I. H. M., Fey, H., Büchel, C., and Van Grondelle, R. (2005). Spectroscopic characterization of the excitation energy transfer in the fucoxanthin-chlorophyll protein of diatoms. Photosyn. Res. 86, 241-250. doi: 10.1007/s11120-005-1003-8

Reichman, J. R., Wilcox, T. P., and Vize, P. D. (2003). PCP Gene Family in Symbiodinium from Hippopus hippopus: low levels of concerted evolution, isoform diversity, and spectral tuning of chromophores. Mol. Biol. Evol. 20, 2143-2154. doi: 10.1093/molbev/msg233

Rowan, R., and Knowlton, N. (1995). Intraspecific diversity and ecological zonation in coral algal symbiosis. Proc. Natl. Acad. Sci. U.S.A. 92, 2850-2853. doi: 10.1073/pnas.92.7.2850

Sampayo, E. M., Franceschinis, L., Hoegh-Guldberg, O., and Dove, S. (2007). Niche partitioning of closely related symbiotic dinoflagellates. Mol. Ecol. 16, 3721-3733. doi: 10.1111/j.1365-294X.2007.03403.x

Santos, S. R., Shearer, T. L., Hannes, A. R., and Coffroth, M. A. (2004). Fine-scale diversity and specificity in the most prevalent lineage of symbiotic dinoflagellates (Symbiodinium, Dinophyceae) of the Caribbean. Mol. Ecol. 13, 459-469. doi: 10.1046/j.1365-294X.2003.02058.x

Schlichter, D., and Fricke, H. W. (1991). Mechanisms of amplification of photosynthetically active radiation in the symbiotic deep-water coral Leptoseris fragilis. Hydrobiologia 216/217, 389-394. doi: 10.1007/BF00026491

Schlichter, D., Fricke, H. W., and Weber, W. (1986). Light harvesting by wavelength transformation in a symbiotic coral of the Red Sea twilight zone. Mar. Biol. 91, 403-407. doi: 10.1007/BF00428634

Silverstein, R. N., Correa, A. M. S., and Baker, A. C. (2012). Specificity is rarely absolute in coral-algal symbiosis: implications for coral response to climate change. Proc. R. Soc. B Biol. Sci. 279, 2609-2618. doi: 10.1098/rspb.2012.0055

Stambler, N., Levy, O., and Vaki, L. (2008). Photosynthesis and respiration of hermatypic zooxanthellate Red Sea corals from 5-75-m depth. Isr. J. Plant Sci. 56, 45-53. doi: 10.1560/IJPS.56.1-2.45

Stimson, J., Sakai, K., and Sembali, H. (2002). Interspecific comparison of the symbiotic relationship in corals with high and low rates of bleaching-induced mortality. Coral Reefs 21, 409-421. doi: 10.1007/s00338-002-0264-3
Thornhill, D. J., Lajeunesse, T. C., and Santos, S. R. (2007). Measuring rDNA diversity in eukaryotic microbial systems: how intragenomic variation, pseudogenes, and PCR artifacts confound biodiversity estimates. Mol. Ecol. 16, 5326-5340. doi: 10.1111/j.1365-294X.2007.03576.x

Thornhill, D. J., Lewis, A., Wham, D., and Lajeunesse, T. (2014). Host specialist lineages dominate the adaptive radiation of reef coral endosymbionts. Evolution 68, 352-367. doi: 10.1111/evo.12270

Wangpraseurt, D., Larkum, A. W., Ralph, P. J., and Kühl, M. (2012). Light gradients and optical microniches in coral tissues. Front. Microbiol. 3:316. doi: 10.3389/fmicb.2012.00316

Ziegler, M., Roder, C., Büchel, C., and Voolstra, C. (2014). Limits to physiological plasticity of the coral Pocillopora verrucosa from the central Red Sea. Coral Reefs. 33, 1115-1129. doi: 10.1007/s00338-0141192-8

Conflict of Interest Statement: The authors declare that the research was conducted in the absence of any commercial or financial relationships that could be construed as a potential conflict of interest.

Received: 26 October 2014; paper pending published: 16 December 2014; accepted: 16 January 2015; published online: 06 February 2015.

Citation: Ziegler M, Roder CM, Büchel C and Voolstra CR (2015) Mesophotic coral depth acclimatization is a function of host-specific symbiont physiology. Front. Mar. Sci. 2:4. doi: 10.3389/fmars.2015.00004

This article was submitted to Marine Molecular Biology and Ecology, a section of the journal Frontiers in Marine Science.

Copyright (c) 2015 Ziegler, Roder, Büchel and Voolstra. This is an open-access article distributed under the terms of the Creative Commons Attribution License (CC BY). The use, distribution or reproduction in other forums is permitted, provided the original author(s) or licensor are credited and that the original publication in this journal is cited, in accordance with accepted academic practice. No use, distribution or reproduction is permitted which does not comply with these terms. 